ARTICLE

\title{
Stabilization of $\varepsilon$-iron carbide as high-temperature catalyst under realistic Fischer-Tropsch synthesis conditions
}

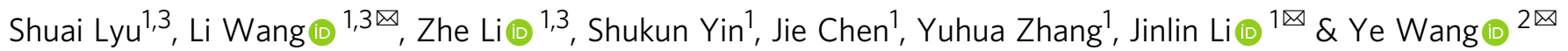

The development of efficient catalysts for Fischer-Tropsch (FT) synthesis, a core reaction in the utilization of non-petroleum carbon resources to supply energy and chemicals, has attracted much recent attention. $\varepsilon$-Iron carbide $\left(\varepsilon-\mathrm{Fe}_{2} \mathrm{C}\right)$ was proposed as the most active iron phase for FT synthesis, but this phase is generally unstable under realistic FT reaction conditions (> $523 \mathrm{~K}$ ). Here, we succeed in stabilizing pure-phase $\varepsilon-\mathrm{Fe}_{2} \mathrm{C}$ nanocrystals by confining them into graphene layers and obtain an iron-time yield of $1258 \mu \mathrm{mol}_{\mathrm{CO}} \mathrm{g}_{\mathrm{Fe}}{ }^{-1} \mathrm{~S}^{-1}$ under realistic FT synthesis conditions, one order of magnitude higher than that of the conventional carbon-supported Fe catalyst. The $\varepsilon-\mathrm{Fe}_{2} \mathrm{C} @ g$ raphene catalyst is stable at least for $400 \mathrm{~h}$ under high-temperature conditions. Density functional theory (DFT) calculations reveal the feasible formation of $\varepsilon-\mathrm{Fe}_{2} \mathrm{C}$ by carburization of $\alpha$-Fe precursor through interfacial interactions of $\varepsilon-\mathrm{Fe}_{2} \mathrm{C} @$ graphene. This work provides a promising strategy to design highly active and stable Fe-based FT catalysts.

\footnotetext{
${ }^{1}$ Key Laboratory of Catalysis and Energy Materials Chemistry of Ministry of Education \& Hubei Key Laboratory of Catalysis and Materials Science, South-Central University for Nationalities, Wuhan 430074, China. ${ }^{2}$ State Key Laboratory of Physical Chemistry of Solid Surfaces, Collaborative Innovation Center of Chemistry for Energy Materials, National Engineering Laboratory for Green Chemical Productions of Alcohols, Ethers and Esters, College of Chemistry and Chemical Engineering, Xiamen University, Xiamen 361005, China. ${ }^{3}$ These authors contributed equally: Shuai Lyu, Li Wang,

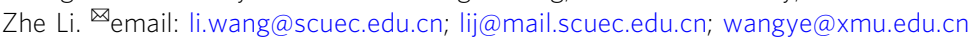


F ischer-Tropsch (FT) synthesis transforms syngas (a mixture of $\mathrm{CO}$ and $\mathrm{H}_{2}$ ) into multi-carbon hydrocarbons, which can be liquid fuels and chemicals. Because FT synthesis is a core reaction in the utilization of various non-petroleum carbon sources (such as coal, natural or shale gas, biomass, and $\mathrm{CO}_{2}$ ) to supply energy and chemicals, the development of efficient FT catalysts has received much-renewed interest in recent years ${ }^{1-6}$. Iron-based catalysts have widely been used in the industrial FT process because of the low cost of iron, wide operation conditions, and flexible product distributions ${ }^{7}$. However, Fe-based catalysts usually suffer from low activity and stability ${ }^{3}$, and thus many recent fundamental studies have been devoted to enhancing the FT activity and stability of $\mathrm{Fe}$ catalysts by employing different modifiers or different supports ${ }^{8-14}$. Unlike Ru- or Co-based FT catalysts, where metallic $\mathrm{Ru}^{0}$ or $\mathrm{Co}^{0}$ functions as the active phase, metallic $\mathrm{Fe}^{0}$ is unstable and the evolution of a conventional $\mathrm{Fe}-$ based catalyst typically results in a mixture of different iron phases including $\mathrm{Fe}_{3} \mathrm{O}_{4}$ and iron carbides under FT reaction conditions ${ }^{15-21}$. Iron carbides are believed to be responsible for the activation of $\mathrm{CO}$ and the chain growth in FT synthesis, but the nature of the true active iron-carbide phase is still under debate and this hinders the rational design of highly active and stable Fe-based FT catalysts.

Hägg $\chi-\mathrm{Fe}_{5} \mathrm{C}_{2}$ has been observed in many Fe-based catalysts after FT reactions or during in situ characterizations ${ }^{22-24}$. These observations form the current consensus that $\chi-\mathrm{Fe}_{5} \mathrm{C}_{2}$ is the active phase for FT synthesis. The pure-phase $\chi-\mathrm{Fe}_{5} \mathrm{C}_{2}$ was also successfully synthesized and was confirmed to be efficient for FT synthesis ${ }^{25,26}$. Theoretical calculations also predicted that $\chi-\mathrm{Fe}_{5} \mathrm{C}_{2}$ surfaces catalyzed the $\mathrm{CO}$ activation and C-C chain growth ${ }^{27,28}$, and $\chi-\mathrm{Fe}_{5} \mathrm{C}_{2}$ should be more active than metallic $\mathrm{Fe}^{27}$. Nevertheless, a recent work disclosed that the octahedral carbide $\varepsilon$ $\mathrm{Fe}_{2} \mathrm{C}$, which contains carbon atoms in octahedral interstices of hexagonal closed-packed iron lattice, was more active than a $\chi$ $\mathrm{Fe}_{5} \mathrm{C}_{2}$-dominant catalyst in the low-temperature $(\leq 473 \mathrm{~K})$ FT reaction ${ }^{29}$. The $\mathrm{Fe}$ catalyst based on $\varepsilon-\mathrm{Fe}_{2} \mathrm{C}$ phase could also decrease the $\mathrm{CO}_{2}$ selectivity during FT synthesis ${ }^{30}$. However, it is known that $\varepsilon-\mathrm{Fe}_{2} \mathrm{C}$ would be transformed into $\chi-\mathrm{Fe}_{5} \mathrm{C}_{2}$ at above $523 \mathrm{~K}$, and thus would be unstable at a higher temperature $(\sim 573 \mathrm{~K})$ that is usually adopted for Fe-catalyzed FT synthesis. Under FT reaction, Fe-based catalysts are usually coated with an amorphous carbon/carbide layer that facilely induces the carbides transformation (Fig. 1a) ${ }^{31,32}$. Thus, it is highly challenging to synthesize stable catalysts that are dominated by the highly active $\varepsilon-\mathrm{Fe}_{2} \mathrm{C}$ phase for FT synthesis.

Here, we attempt to replace the amorphous carbon with few graphene layers that confines the Fe-based catalyst. The confinement of the rigid geometry of the graphene shell can inhibit

a

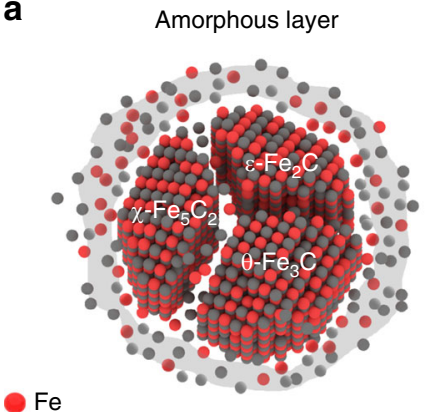

C

Fig. 1 Schematic models of iron-based catalysts for Fischer-Tropsch synthesis. a Conventional catalysts with unconfined iron carbide $\left(\mathrm{Fe}_{x} \mathrm{C}\right)$ particles as the active phase. $\mathbf{b}$ Graphene layer-confined $\varepsilon-\mathrm{Fe}_{2} \mathrm{C}$. the formation of the amorphous carbon layer and improve the stability of highly active $\varepsilon$ - $\mathrm{Fe}_{2} \mathrm{C}$ (Fig. 1b). We report our finding that the confinement of $\varepsilon-\mathrm{Fe}_{2} \mathrm{C}$ inside graphene layers (denoted as $\left.\varepsilon-\mathrm{Fe}_{2} \mathrm{C} @ g r a p h e n e\right)$ can stabilize this metastable phase for FT synthesis at $523-613 \mathrm{~K}$. The Fe-time yield (FTY), which is defined as the moles of $\mathrm{CO}$ converted to hydrocarbons per gram of $\mathrm{Fe}$ per second, reaches $1258 \mu \mathrm{mol}_{\mathrm{CO}} \mathrm{g}_{\mathrm{Fe}}{ }^{-1} \mathrm{~s}^{-1}$ at $613 \mathrm{~K}$, breaking the upper-limit value $\left(1000 \mu \mathrm{mol}_{\mathrm{CO}} \mathrm{g}_{\mathrm{Fe}}{ }^{-1} \mathrm{~s}^{-1}\right)$ reported for Fe-based FT catalysts 12,13 . The catalyst is highly stable under our FT reaction conditions and high CO conversion $(\sim 95 \%)$ can be kept at $573 \mathrm{~K}$ at least for $400 \mathrm{~h}$. DFT calculations suggest that the confinement effects of graphene layers favor the formation of $\varepsilon$ $\mathrm{Fe}_{2} \mathrm{C}$ from carburization of $\alpha-\mathrm{Fe}$, which maintains the high stability of $\varepsilon-\mathrm{Fe}_{2} \mathrm{C}$ under high-temperature FT reaction conditions. On the other hand, the facile transformation of $\mathrm{Fe}_{x} \mathrm{C}$ particles may occur during FT synthesis over the conventional FT catalyst. To the best of our knowledge, this is the first example to demonstrate experimentally that the $\varepsilon-\mathrm{Fe}_{2} \mathrm{C}$ phase can be stabilized under high-temperature FT reaction conditions. The present work provides a promising strategy to synthesize highly active and stable Fe-based FT catalysts and offers an opportunity for the study of FT reactions on pure metastable-phase iron carbides.

\section{Results}

Catalysts structure and structure evolution. Our confined iron carbide catalyst was synthesized by a pyrolysis method, followed by reduction with $\mathrm{H}_{2}$ and carburization in syngas flow. X-ray diffraction (XRD) measurements and ${ }^{57} \mathrm{Fe}$ Mössbauer spectroscopy showed that $\theta-\mathrm{Fe}_{3} \mathrm{C}$ was the major Fe phase in the precursor obtained after pyrolysis (Fig. 2a, b). Transmission electron microscopy (TEM) results clarified that most of the iron carbide nanoparticles were well dispersed with a near-spherical morphology and had a mean size of $13.6 \mathrm{~nm}$ (Supplementary Fig. 1a). The high-resolution TEM (HRTEM) studies revealed that the $\theta$ $\mathrm{Fe}_{3} \mathrm{C}$ nanoparticles were surrounded and closely attached by graphene layers (Fig. $2 \mathrm{c}$ and Supplementary Fig. 1b). The lattice fringes with $d$ spacing values of 0.30 and $0.34 \mathrm{~nm}$, which corresponded to the (111) facet of $\theta-\mathrm{Fe}_{3} \mathrm{C}$ and the (002) facet of graphene, respectively, were observed (the insert of Supplementary Fig. 1b). These results indicate that the precursor obtained after pyrolysis is in the structure of $\theta-\mathrm{Fe}_{3} \mathrm{C} @$ graphene.

After the reduction by $\mathrm{H}_{2}$ at $623 \mathrm{~K}, \alpha-\mathrm{Fe}$ became the major iron phase, indicating that $\theta-\mathrm{Fe}_{3} \mathrm{C}$ was decomposed into $\mathrm{Fe}$ (Fig. 2a). This was also confirmed from HRTEM images, showing that the nanoparticle of $\alpha-\mathrm{Fe}$ remains encapsulated by graphene layers after the reduction. The carburization of $\alpha$-Fe@graphene under syngas at $573 \mathrm{~K}$ transformed $\alpha$-Fe into iron carbide again (denoted as $\varepsilon-\mathrm{Fe}_{2} \mathrm{C} @$ graphene-C). It is of interest that $\varepsilon$-iron carbide $\left(\varepsilon-\mathrm{Fe}_{2} \mathrm{C}\right)$ rather than $\theta-\mathrm{Fe}_{3} \mathrm{C}$ or $\chi-\mathrm{Fe}_{5} \mathrm{C}_{2}$ was formed after the carburization (Fig. 2a). The HRTEM result reveals that the $\varepsilon$ iron carbide is surrounded by the graphene layers (Fig. 2d). It can be clearly seen by spherical aberration-corrected scanning transmission electron microscopes (Cs-corrected STEM) that the graphene layers of $\varepsilon-\mathrm{Fe}_{2} \mathrm{C} @$ graphene catalyst are about 2-7 layers and a large number of defects spread over carbon layer outside $\varepsilon-\mathrm{Fe}_{2} \mathrm{C} @$ graphene catalyst (Supplementary Fig. 2).

For graphene layers covered metal catalysts, it was demonstrated that defects on graphene layers render the channels for the diffusion of active species through the grain boundaries on the metal surface ${ }^{33}$. Molecules such as $\mathrm{CO}, \mathrm{H}_{2}$, and $\mathrm{H}_{2} \mathrm{O}$ can go through domain boundaries and point defects (such as pentagonheptagon defects and vacancies) on the 2D material overlayers, which mainly follow the defect-aided intercalation mechanism ${ }^{34}$. In addition, the Raman spectra of $\varepsilon-\mathrm{Fe}_{2} \mathrm{C} @$ graphene catalyst show that the $2 \mathrm{D}$ peak position of $\varepsilon-\mathrm{Fe}_{2} \mathrm{C} @$ graphene blueshifted 

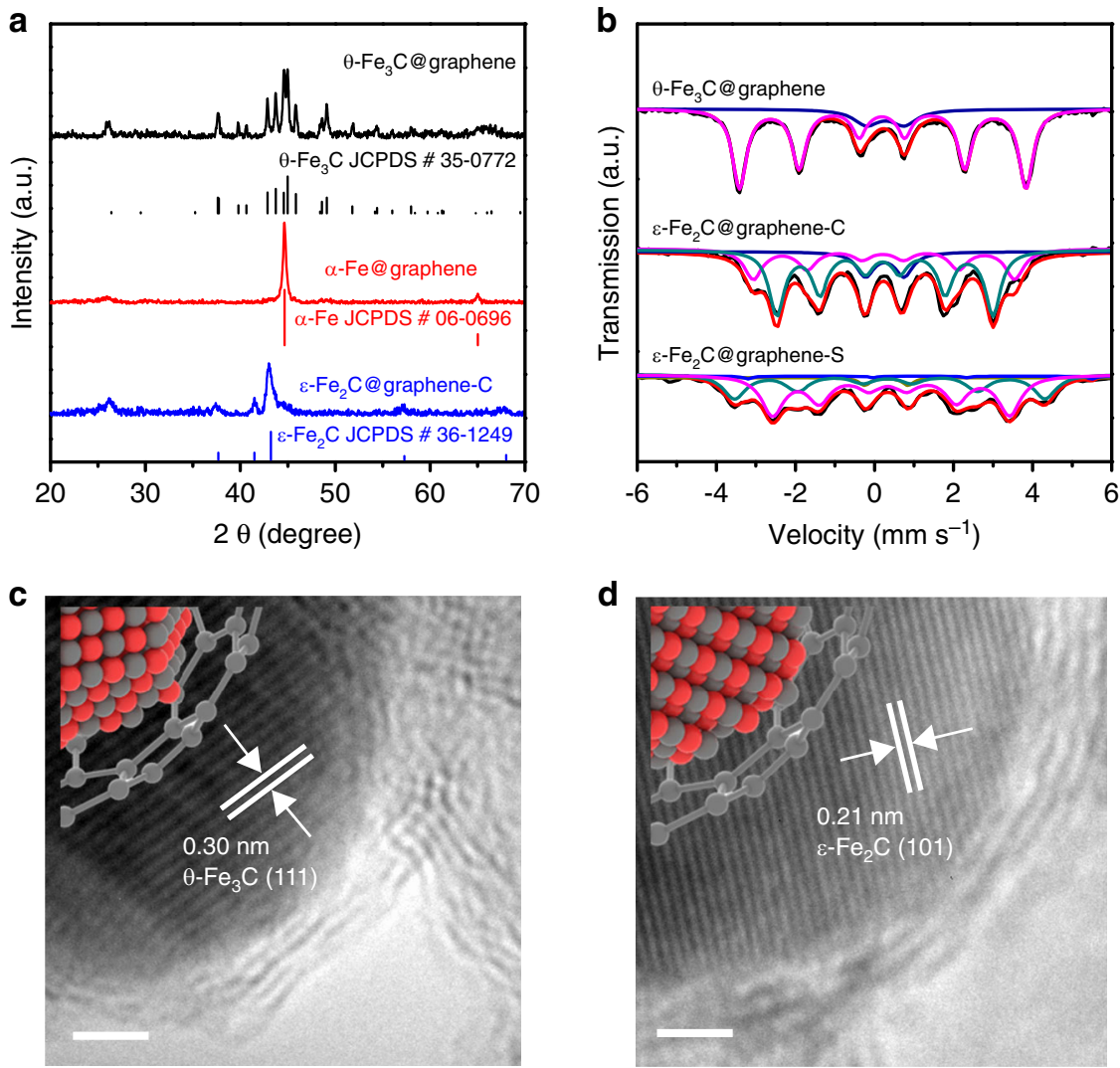

Fig. 2 Structure of $\boldsymbol{\theta}-\mathbf{F e}_{3} \mathbf{C} @ g$ graphene and $\boldsymbol{\varepsilon}-\mathbf{F e}_{\mathbf{2}} \mathbf{C} @$ graphene samples. a XRD diffraction patterns for $\theta-\mathrm{Fe}_{3} \mathrm{C} @$ graphene sample (black line), $\theta$ $\mathrm{Fe}_{3} \mathrm{C} @$ graphene sample reduction under flowing $\mathrm{H}_{2}$ at $623 \mathrm{~K}$ for $3 \mathrm{~h}$ (red line), and then carbonization under flowing syngas $\left(\mathrm{H}_{2} / \mathrm{CO}=1\right)$ at $573 \mathrm{~K}$ for $10 \mathrm{~h}$ (blue line).b57 ${ }^{5 e}$ Mössbauer spectra for $\theta-\mathrm{Fe}_{3} \mathrm{C} @$ graphene, $\varepsilon-\mathrm{Fe}_{2} \mathrm{C} @ g$ graphene- $\mathrm{C}$, and $\varepsilon-\mathrm{Fe}_{2} \mathrm{C} @$ graphene- $\mathrm{S}$ samples. Representative high-resolution TEM micrographs for $\mathbf{c} \theta-\mathrm{Fe}_{3} \mathrm{C} @ g$ graphene and $\mathbf{d} \varepsilon-\mathrm{Fe}_{2} \mathrm{C} @ g r a p h e n e-\mathrm{C}$. Scale bar, $2 \mathrm{~nm}$.

a

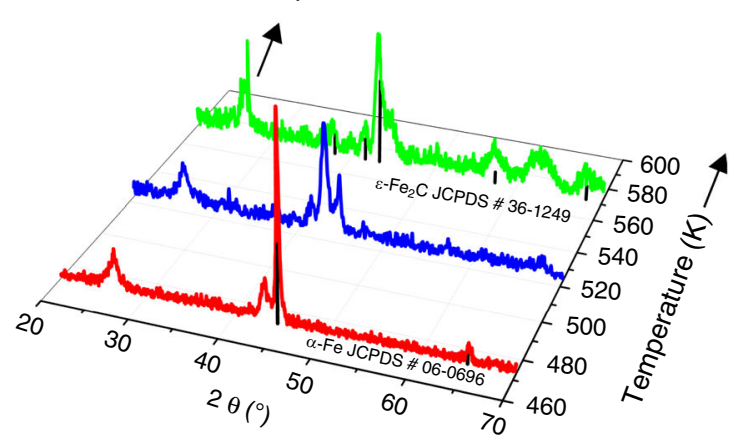

b

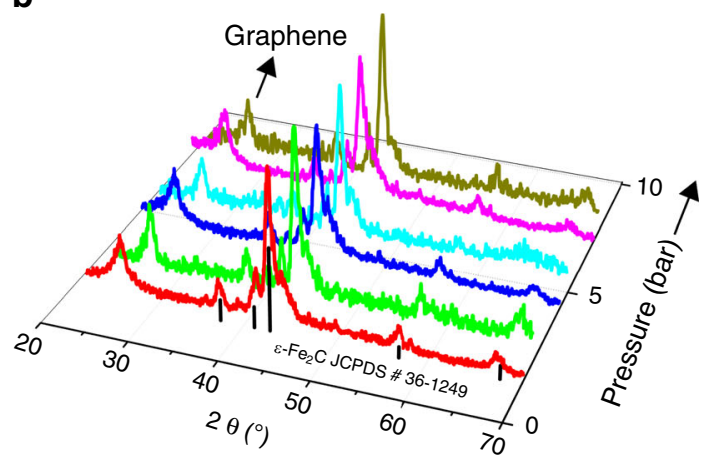

Fig. 3 XRD patterns for $\boldsymbol{\theta}-\mathrm{Fe}_{3} \mathbf{C} @ g$ graphene samples. a $\theta-\mathrm{Fe}_{3} \mathrm{C} @$ graphene samples reduction under flowing $\mathrm{H}_{2}$ at $623 \mathrm{~K}$ for $3 \mathrm{~h}$, and then treated under

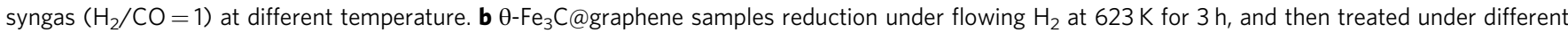
CO pressure at $573 \mathrm{~K}$.

relative to single-layer graphene and the peak pattern consistent to the few graphene layers rather than bulk graphite (Supplementary Fig. 3).

${ }^{57} \mathrm{Fe}$ Mössbauer spectroscopy of $\varepsilon-\mathrm{Fe}_{2} \mathrm{C} @$ graphene-C provided further evidence for the formation of $\varepsilon-\mathrm{Fe}_{2} \mathrm{C}$ after the carburization (Fig. $2 \mathrm{~b}$ and Supplementary Table 1). Moreover, after $100 \mathrm{~h}$ reaction in syngas at $573 \mathrm{~K}$ (denoted as $\varepsilon-\mathrm{Fe}_{2} \mathrm{C} @$ graphene-S), the $\varepsilon-\mathrm{Fe}_{2} \mathrm{C}$ content remained constant (about 62.8\%), indicating the stabilizing effect by the graphic carbon layer on $\varepsilon-\mathrm{Fe}_{2} \mathrm{C}$ even under reaction conditions (Fig. $2 \mathrm{~b}$ and Supplementary Table 1).

To gain further insights into the possible evolution of iron phases, we have performed in situ XRD characterizations for our sample in syngas flow under different conditions. $\alpha$-Fe was still the major phase under syngas with a $\mathrm{H}_{2} / \mathrm{CO}$ ratio of 1 at $473 \mathrm{~K}$ and was gradually changed to $\varepsilon-\mathrm{Fe}_{2} \mathrm{C}$ phase upon increasing the temperature from 473 to $573 \mathrm{~K}$ (Fig. $3 \mathrm{a}$ ). In addition, during the carburization process, $\varepsilon$ $\mathrm{Fe}_{2} \mathrm{C}$ phase kept stable in syngas flow at $573 \mathrm{~K}$ for $5 \mathrm{~h}$ and remained almost unchanged by changing the $\mathrm{CO}$ pressure at $573 \mathrm{~K}$ (Fig. $3 \mathrm{~b}$ ). It is noteworthy that conventionally $\varepsilon-\mathrm{Fe}_{2} \mathrm{C}$ is unstable and would be converted to $\chi-\mathrm{Fe}_{5} \mathrm{C}_{2}$ and $\theta-\mathrm{Fe}_{3} \mathrm{C}$ at $\geq 523 \mathrm{~K}^{20}$. Interestingly, we observed the formation of $\varepsilon-\mathrm{Fe}_{2} \mathrm{C}$ phase in a wide range of temperature and $\mathrm{CO}$ pressure, which are closely related to the model of carbon chemical potential $\left(\mu_{\mathrm{C}}\right)$ as explained in the computational details of Supplementary Methods. Thus, the present results 
Table 1 Activity and hydrocarbon selectivity of different iron carbides catalysts for Fischer-Tropsch synthesisa.

\begin{tabular}{|c|c|c|c|c|c|c|c|c|}
\hline Catalyst & $\begin{array}{l}\text { FTY } \\
(\mu \mathrm{mol} \\
\left.\mathrm{Co}_{\mathrm{Fe}} \mathrm{g}^{-1} \mathrm{~s}^{-1}\right)\end{array}$ & $\mathrm{CO}_{2}$ sel. (\%) & $\begin{array}{l}\text { O/P ratio } \\
\left(C_{2}-C_{4}\right)\end{array}$ & $\mathrm{CH}_{4}$ sel. (\%) & $\begin{array}{l}C_{2}-C_{4} \\
\text { sel. (\%) }\end{array}$ & $\mathrm{C}_{5}+$ sel. (\%) & $\begin{array}{l}\text { TOF c } \\
\left(\mathrm{s}^{-1}\right) \times 10^{2}\end{array}$ & $\begin{array}{l}\text { TOF d } \\
\left(s^{-1}\right) \times 10^{2}\end{array}$ \\
\hline
\end{tabular}

aReaction conditions: $\mathrm{H}_{2} / \mathrm{CO}=1 / 1,573 \mathrm{~K}, p=10$ bar.

${ }^{b}{ }_{\chi}-\mathrm{Fe}_{5} \mathrm{C}_{2}$ was obtained from the $\theta-\mathrm{Fe}_{3} \mathrm{C} @ g$ graphene sample by oxidation at $723 \mathrm{~K}$ for $5 \mathrm{~h}$ in air, and then carbonization under flowing syngas $\left(\mathrm{H}_{2} / \mathrm{CO}=1\right)$ at $573 \mathrm{~K}$ for $10 \mathrm{~h}($ the sample without carbon encapsulation denoted as $\chi-\mathrm{Fe}_{5} \mathrm{C}_{2}$ ).

'Based on $\mathrm{CO}$ chemisorption.

dBased on iron carbide particle size ${ }^{41}$, and calculated by using the densities of $\varepsilon-\mathrm{Fe}_{2} \mathrm{C}, \chi-\mathrm{Fe}_{5} \mathrm{C}$, and $\theta-\mathrm{Fe}_{3} \mathrm{C}$ of $7.19 \mathrm{~g} \mathrm{~mL}^{-1}, 7.57 \mathrm{~g} \mathrm{~mL}^{-1}$, and $7.68 \mathrm{~g} \mathrm{~mL}^{-1}$ respectively, and by assuming $14 \mathrm{Fe}$ atoms $\mathrm{nm}^{-2}$.

clearly demonstrate that the confinement of $\varepsilon-\mathrm{Fe}_{2} \mathrm{C}$ inside graphene layers can keep it from phase transformations probably.

For comparison, we further studied the changes in structures of $\theta-\mathrm{Fe}_{3} \mathrm{C} @$ graphene samples before and after treatment under different conditions (Supplementary Fig. 4). The direct carburization of $\theta-\mathrm{Fe}_{3} \mathrm{C} @$ graphene did not induce any detectable change in the phase composition, probably because this sample was formed by a prior carburization process. $\mathrm{Fe}_{2} \mathrm{O}_{3}$ was obtained by oxidation of $\theta-\mathrm{Fe}_{3} \mathrm{C} @$ graphene and served as a carbon encapsulation-free reference. The carburization treatment of $\mathrm{Fe}_{2} \mathrm{O}_{3}$ led to the formation of $\mathrm{Fe}_{3} \mathrm{O}_{4}$ and $\chi-\mathrm{Fe}_{5} \mathrm{C}_{2}$. The characterization result shows that only $\chi-\mathrm{Fe}_{5} \mathrm{C}_{2}$ could be observed at $573 \mathrm{~K}$, which is the thermodynamic stable phase at high temperatures. On the other hand, the carbon-encapsulated metal Fe sample only formed the $\varepsilon-\mathrm{Fe}_{2} \mathrm{C}$ phase after the carburization treatment. The $\varepsilon-\mathrm{Fe}_{2} \mathrm{C}$ phase can be stabilized by the graphene layer even at such a high temperature.

Raman spectroscopy was used to identify the nature of the graphene layers. Two bands at 1350 and $1590 \mathrm{~cm}^{-1}$ were observed in the Raman spectra for $\varepsilon-\mathrm{Fe}_{2} \mathrm{C} @$ graphene-C and $\varepsilon$ $\mathrm{Fe}_{2} \mathrm{C} @ g r a p h e n e-\mathrm{S}$, corresponding to the D-band (disordered carbon) and the G-band (graphene carbon), respectively (Supplementary Fig. 5). A lower $I_{\mathrm{D}} / I_{G}$ intensity ratio for the $\varepsilon$ $\mathrm{Fe}_{2} \mathrm{C} @ g r a p h e n e$ was observed, consistent with a higher degree of graphene of the carbon matrix ${ }^{35}$. The $2 \mathrm{D}$ bands of the two $\varepsilon$ $\mathrm{Fe}_{2} \mathrm{C} @ g r a p h e n e$ samples are closely related to the band structure of graphene layers ${ }^{36}$. These observations suggest that while the iron phase undergoes changes under different atmospheres, the graphene layers keep surrounding the particle of iron or iron carbide.

In addition, the surface composition of the graphene layers is of particular interest and surface contents of $\mathrm{N}, \mathrm{O}$, and Fe were determined by X-ray photoelectron spectroscopy (XPS). The $\theta$ $\mathrm{Fe}_{3} \mathrm{C} @ g r a p h e n e$ sample has a surface atomic ration of $\mathrm{Fe} / \mathrm{C}$ of about 0.03 , and the surface contents of $\mathrm{N}, \mathrm{O}$, and Fe elements did not vary with an increase of the Fe loading in the catalysts (Supplementary Table 2). The results revealed a negligible surface iron content, suggesting that $\theta-\mathrm{Fe}_{3} \mathrm{C}$ nanoparticles were encapsulated by the graphene layers in the catalysts.

XPS characterizations were further performed to analyze carbon and nitrogen bonding configurations in the carburization process of Fe@graphene. N 1s peaks in XPS of $\theta-\mathrm{Fe}_{3} \mathrm{C} @ g r a p h e n e$ (Supplementary Fig. 6a, b) can be fitted into four peaks at 398.3 $\mathrm{eV}, 399.6 \mathrm{eV}, 400.8 \mathrm{eV}$, and $402.5 \mathrm{eV}$ referring to the pyridinic, pyrrolic, graphitic and oxidized nitrogen, respectively ${ }^{37}$. These results confirmed the existence of $\mathrm{N}$ functional groups (pyridinic$\mathrm{N}$, pyrrolic- $\mathrm{N}$, and graphitic-N), indicating unique defect-rich structure graphene layers after the annealing process. Moreover, the XPS results clearly confirmed the presence of defective graphene layers during the reducing and carburization processes (Supplementary Fig. 6c, e) and the incorporation of nitrogen atoms within the graphene layers (Supplementary Fig. 6d, f). From the above Raman spectra, STEM/HRTEM images, and
XPS results, we conclude that the highly defective graphene layers have been successfully synthesized during the thermal annealing. The number of defects and type of doped $\mathrm{N}$ in carbons might play a crucial role in enhancing FT reaction catalytic performance ${ }^{38,39}$. $\mathrm{N}$ 1s XPS spectra of the few graphene layers confined iron catalysts reveals that the graphitic $\mathrm{N}$ is the most abundant $\mathrm{N}$ species, indicating that the graphitic $\mathrm{N}$ could affect the performance of confined iron catalysts, which is rationalized by our theoretical modeling shown in the part of DFT calculation.

Catalytic performance of $\varepsilon-\mathrm{Fe}_{2} \mathrm{C}$ phase in high-temperature FT synthesis. It was once reported that the activity of $\varepsilon-\mathrm{Fe}_{2} \mathrm{C}$ nanoparticles is 4.3 times that of $\chi-\mathrm{Fe}_{5} \mathrm{C}_{2}$ and is even comparable to that of the precious metal Ru for FT synthesis, probably owing to its excellent ability to dissociate $\mathrm{CO}^{29}$. Unfortunately, the study of the catalytic performance of $\varepsilon-\mathrm{Fe}_{2} \mathrm{C}$ under practical FT reaction conditions is limited because of its metastable state.

Here, the thermal stability $\varepsilon-\mathrm{Fe}_{2} \mathrm{C} @$ graphene enables us to investigate its catalytic performance at $573 \mathrm{~K}$. The FTY value of $\varepsilon$ $\mathrm{Fe}_{2} \mathrm{C} @ g r a p h e n e$ at $573 \mathrm{~K}$ was $582.8 \mu \mathrm{mol}_{\mathrm{CO}} \mathrm{g}_{\mathrm{Fe}}{ }^{-1} \mathrm{~s}^{-1}$ (Table 1), which was significantly higher than those for the un-encapsulated $\chi-\mathrm{Fe}_{5} \mathrm{C}_{2}$ derived from $\mathrm{Fe}_{2} \mathrm{O}_{3}$ and the $\theta-\mathrm{Fe}_{3} \mathrm{C} @$ graphene catalysts. The intrinsic activity (TOF values) of $\varepsilon-\mathrm{Fe}_{2} \mathrm{C}$ is $\sim 6-10$ times higher than the $\theta-\mathrm{Fe}_{3} \mathrm{C}$ and 2 times higher than the $\chi-\mathrm{Fe}_{5} \mathrm{C}_{2}$. Furthermore, CO-TPD profiles of $\varepsilon-\mathrm{Fe}_{2} \mathrm{C} @$ graphene catalyst show a multi-peak overlapped cure with a maximum peak position at $c a .843 \mathrm{~K}$, which is attributed to desorption of CO after recombination of dissociated carbon and oxygen on the surface (Supplementary Fig. 7). The result revealed the strongly bound $\mathrm{CO}$ on the surface due to the confinement effect of $\varepsilon$ $\mathrm{Fe}_{2} \mathrm{C} @$ graphene catalyst. In addition, the $\mathrm{CO}_{2}$ selectivity for the $\varepsilon-\mathrm{Fe}_{2} \mathrm{C} @$ graphene catalyst was lower than those for the other two reference catalysts, indicating that the $\varepsilon-\mathrm{Fe}_{2} \mathrm{C}$ is a more active and selective phase for the conversion of syngas to hydrocarbons.

The $\varepsilon-\mathrm{Fe}_{2} \mathrm{C} @ g r a p h e n e$ catalysts with different Fe loadings all showed very high activities. The FTY value for the $\varepsilon$ $\mathrm{Fe}_{2} \mathrm{C} @$ graphene catalysts with $\mathrm{Fe}$ loadings in a range of 10-50 wt $\%$ is almost the same $\left(\sim 600 \mu \mathrm{mol}_{\mathrm{CO}} \mathrm{g}_{\mathrm{Fe}}{ }^{-1} \mathrm{~s}^{-1}\right)$ under the same reaction condition. On the other hand, the FTY value of reference $\mathrm{Fe} / \mathrm{C}$ catalysts decreased sharply upon increasing $\mathrm{Fe}$ loading probably due to the aggregation of Fe species and the oxidation of the active carbide phase under reaction conditions (Fig. 4a $)^{40,41}$. The keeping of high FTY value at high Fe loading suggests that the high dispersion of $\varepsilon-\mathrm{Fe}_{2} \mathrm{C}$ phase in the $\varepsilon-\mathrm{Fe}_{2} \mathrm{C} @$ graphene catalyst is sustained at high $\mathrm{Fe}$ loadings and the $\varepsilon-\mathrm{Fe}_{2} \mathrm{C}$ keeps stable during FT reaction. The FTY value of $\varepsilon-\mathrm{Fe}_{2} \mathrm{C} @$ graphene with iron loading of $40.5 \mathrm{wt} \%$ reached $1258 \mu \mathrm{mol}_{\mathrm{CO}} \mathrm{g}_{\mathrm{Fe}}{ }^{-1} \mathrm{~s}^{-1}$ when the gas-hour space velocity (GHSV) was increased to $160 \mathrm{~L}$ $\mathrm{g}_{\mathrm{cat}}{ }^{-1} \mathrm{~h}^{-1}$ at $613 \mathrm{~K}$ (Fig. 4a). The FTY values reported to date are limited at $1000 \mu \mathrm{mol}_{\mathrm{CO}} \mathrm{g}_{\mathrm{Fe}}{ }^{-1} \mathrm{~s}^{-1}$ (Supplementary Table 3) and 

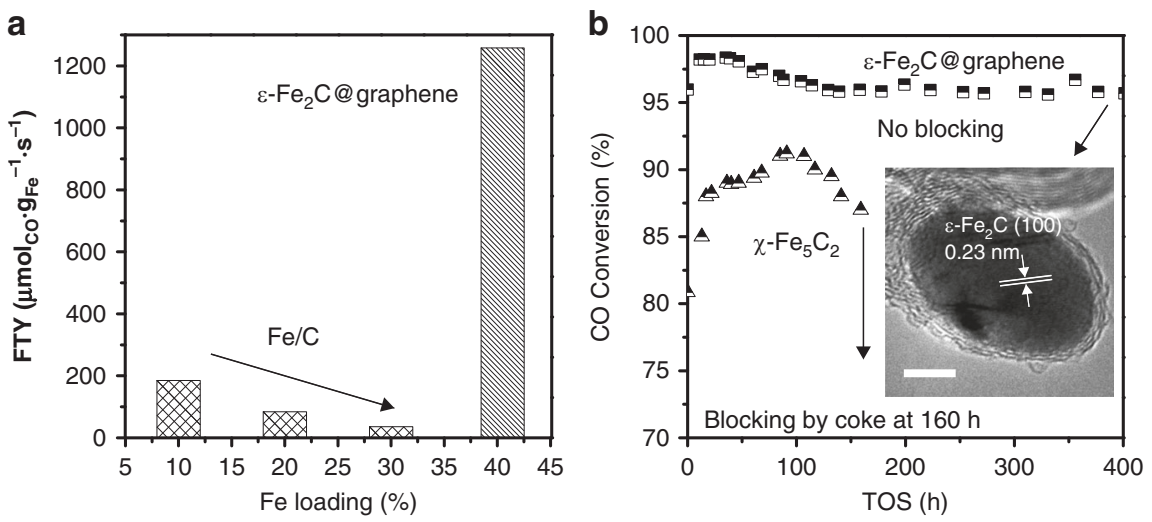

Fig. 4 Catalytic performance of different iron catalysts. a Comparison of FTY values between $\varepsilon-\mathrm{Fe}_{2} \mathrm{C} @ g$ graphene catalyst and iron catalyst loaded on active carbon with different iron loadings. b Long-term stability of $\varepsilon-\mathrm{Fe}_{2} \mathrm{C} @ g r a p h e n e$ and un-encapsulated $\chi$ - $\mathrm{Fe}_{5} \mathrm{C}_{2}$ catalysts. Reaction conditions: $\mathrm{H}_{2} / \mathrm{CO}$ $=1 / 1,573 \mathrm{~K}, p=10$ bar. The insert shows the high-resolution TEM micrograph for the spent $\varepsilon-\mathrm{Fe}_{2} \mathrm{C} @ g r a p h e n e$ catalysts after $400 \mathrm{~h}$ reaction. Scale bar, $5 \mathrm{~nm}$.

the FTY value obtained using the $\varepsilon-\mathrm{Fe}_{2} \mathrm{C} @ g r a p h e n e$ catalyst breaks this limitation.

Time-on-steam evolution of $\mathrm{CO}$ conversion for $\varepsilon-\mathrm{Fe}_{2} \mathrm{C}$ and $\chi$ $\mathrm{Fe}_{5} \mathrm{C}_{2}$ at the same conversion $(\sim 50 \%)$ with different GHSVs revealed that the $\varepsilon-\mathrm{Fe}_{2} \mathrm{C} @$ graphene is much more active than $\chi$ $\mathrm{Fe}_{5} \mathrm{C}_{2}$ in FT synthesis, as shown in Supplementary Fig. 8. It was also found that the carburization of Fe@graphene into $\varepsilon$ $\mathrm{Fe}_{2} \mathrm{C} @$ graphene was completed during $50 \mathrm{~h}$ at GHSV of $64.0 \mathrm{~L}$ $\mathrm{g}_{\mathrm{cat}}{ }^{-1} \mathrm{~h}^{-1}$. For evaluation of catalyst deactivation, we have performed long-termed FT reactions for both $\varepsilon$ - $\mathrm{Fe}_{2} \mathrm{C} @$ graphene and un-encapsulated $\chi-\mathrm{Fe}_{5} \mathrm{C}_{2}$ catalysts at $573 \mathrm{~K}$ under harsh conditions (Fig. 4b). The CO conversion underwent a significant decrease when the time-on-steam exceeded $100 \mathrm{~h}$ for the unencapsulated $\chi-\mathrm{Fe}_{5} \mathrm{C}_{2}$ catalyst and this catalyst was covered by carbon. The pressure drop across the un-encapsulated $\chi-\mathrm{Fe}_{5} \mathrm{C}_{2}$ catalyst bed increased after $100 \mathrm{~h}$ and the gas flow was totally blocked at $160 \mathrm{~h}$, as shown in Fig. $4 \mathrm{~b}$. On the other hand, the encapsulated $\varepsilon-\mathrm{Fe}_{2} \mathrm{C}$ sample was stable for more than $400 \mathrm{~h}$ even at a higher CO conversion ( 95\%). Further, the pressure drop across the $\varepsilon-\mathrm{Fe}_{2} \mathrm{C} @$ graphene catalyst bed was negligible even at high conversion, indicating that the coke deposition on this catalyst was significantly suppressed by the graphene layers under harsh condition.

Furthermore, the selectivity toward olefins and long-chain hydrocarbons also did not undergo significant changes during the long-term reaction. The hydrocarbon distribution over the $\varepsilon$ $\mathrm{Fe}_{2} \mathrm{C} @$ graphene catalyst follows the Anderson-Schulz-Flory distribution (Supplementary Fig. 9). Our Raman studies for the catalyst after reaction showed that the graphene layers and $\varepsilon-\mathrm{Fe}_{2} \mathrm{C}$ phase did not undergo significant changes (Supplementary Fig. 5). The morphology and crystalline structure of the $\varepsilon$ $\mathrm{Fe}_{2} \mathrm{C} @$ graphene catalyst also kept almost unchanged after $400 \mathrm{~h}$ reaction.

DFT calculation of graphene confinement on $\varepsilon-\mathrm{Fe}_{2} \mathrm{C}$. The effects of a graphene layer on the surface stability and carburization feasibility of $\varepsilon-\mathrm{Fe}_{2} \mathrm{C}$ phases were investigated by ab initio atomic thermodynamics based on DFT calculations. The relative chemical potential of carbon $\left(\Delta \mu_{\mathrm{C}}\right)$ is relevant in describing the thermodynamics of iron carbides, which can be determined from the equilibrium of carburization reactions of different gas atmospheres for pretreatment or FT reaction at some temperatures and pressures. Higher temperature and lower pressure, as well as higher $\mathrm{H}_{2} / \mathrm{CO}$ ratio, result in lower $\Delta \mu_{\mathrm{C}}$ value indicating a lower carburization ability (Fig. $5 \mathrm{a}, \mathrm{b}$ ). Based on $\Delta \mu_{\mathrm{C}}$, the carbon absorption energy $\left(E_{\mathrm{abs}}\right)$ can be derived for describing the carburization reaction from metallic Fe to iron carbide. The volume-normalized carbon absorption energy $\left(\Omega_{\mathrm{abs}}\right)$ was applied to the bulk iron carbides ${ }^{20}$.

Here, we develop a surface-normalized carbon absorption energy $\left(\omega_{\text {abs }}\right)$, which is suitable for describing the surface carburization of iron carbide with and without graphene confinement. The most abundant (101), (1-21), and (2-21) surfaces were selected to evaluate the confinement effects of graphene layers on the $\omega_{\text {abs }}$ (Fig. $5 \mathrm{c}$ ). The negative $\omega_{\text {abs }}$ values indicate the favorable stability of the $\varepsilon-\mathrm{Fe}_{2} \mathrm{C}$ surfaces under the conditions of pretreatment and $\mathrm{FT}$ reaction. Although the surface stability follows the order of $(101)>(1-21)>(2-21)$ according to the calculated surface energy (Supplementary Table 4), the (1-21) has the highest carburization feasibility from metallic iron because of the lowest $\omega_{\text {abs }}$ value.

On the other hand, the confinement effects are modeled by covering the $\varepsilon-\mathrm{Fe}_{2} \mathrm{C}$ surfaces with a single graphene layer. The optimized distance between $\varepsilon-\mathrm{Fe}_{2} \mathrm{C}$ and graphene is $c a$. 3.9-4.3 $\mathrm{A}$ (Fig. $5 \mathrm{c}$ ) close to the dynamic diameter of reactants and singlechain hydrocarbons ${ }^{42,43}$, which can afford the catalytic FT reaction on the $\varepsilon-\mathrm{Fe}_{2} \mathrm{C}$ surfaces with the graphene confinements. The $\omega_{\text {abs }}$ values for the graphene-covered $\varepsilon-\mathrm{Fe}_{2} \mathrm{C}$ are lower than those of the pristine $\varepsilon-\mathrm{Fe}_{2} \mathrm{C}$ surfaces, indicating the improved thermodynamic stability. The $\mathrm{N}$-doped graphene (graphene- $\mathrm{N}$ ) show similar results to those of graphene.

In addition, taking (1-21) as an example, we further investigate the mechanism of $\mathrm{CO}$ dissociation on the $\varepsilon-\mathrm{Fe}_{2} \mathrm{C}$ surface with and without graphene confinement. Both the direct and $\mathrm{H}$-assisted dissociations are considered including different active sites of perfect $\varepsilon-\mathrm{Fe}_{2} \mathrm{C}$, graphene, and the $\mathrm{C}$-vacancy on $\varepsilon-\mathrm{Fe}_{2} \mathrm{C}$ (Supplementary Figs. 11-15). The C-vacancy on $\varepsilon-\mathrm{Fe}_{2} \mathrm{C}$ is more active for the direct $\mathrm{CO}$ dissociation with a lower energy barrier $\left(E_{\mathrm{a}}\right)$ of $c a .1 .2 \mathrm{eV}$ than those of direct and $\mathrm{H}$-assisted dissociations (2.57-2.61 and $2.83-2.87 \mathrm{eV})$ on the perfect $\varepsilon-\mathrm{Fe}_{2} \mathrm{C}$ surface with and without the confinement of graphene. The $\mathrm{CO}$ dissociation on the graphene site hardly occurs due to the high $E_{\mathrm{a}}$ values (> $2.89 \mathrm{eV})$. Similar results can be found for graphene-N. The confinement of graphene or graphene(-N) favors to improve the stability of the highly active $\varepsilon-\mathrm{Fe}_{2} \mathrm{C}$ to achieve the high catalytic performance of FT at high temperature.

\section{Discussion}

In summary, we synthesized graphene layers encapsulated $\varepsilon-\mathrm{Fe}_{2} \mathrm{C}$ nanocrystals for the FT reaction. It exhibited remarkably activity $\left(\sim 1258 \mu \mathrm{mol}_{\mathrm{CO}} \mathrm{g}_{\mathrm{Fe}}{ }^{-1} \mathrm{~s}^{-1}\right)$ and stability $(>400 \mathrm{~h})$ under realistic FT synthesis conditions. The confinement effects of graphene 
a

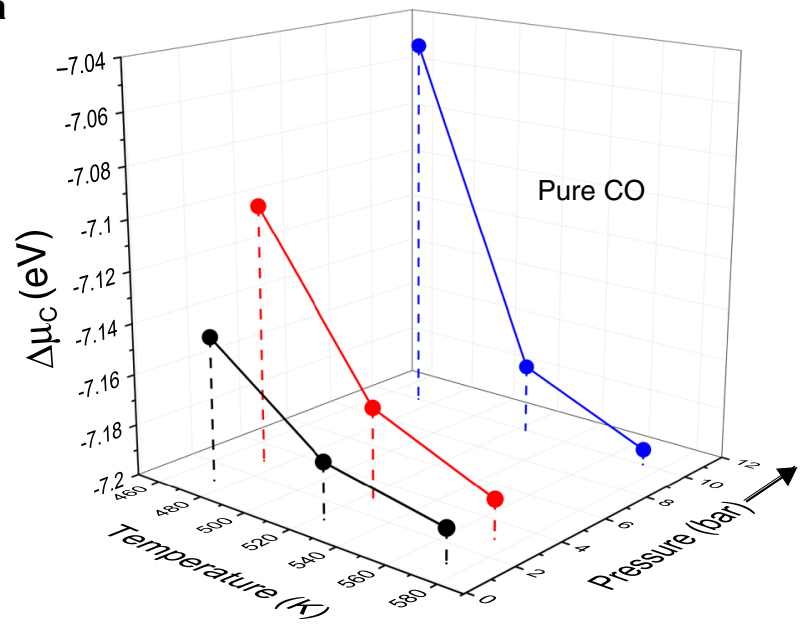

b

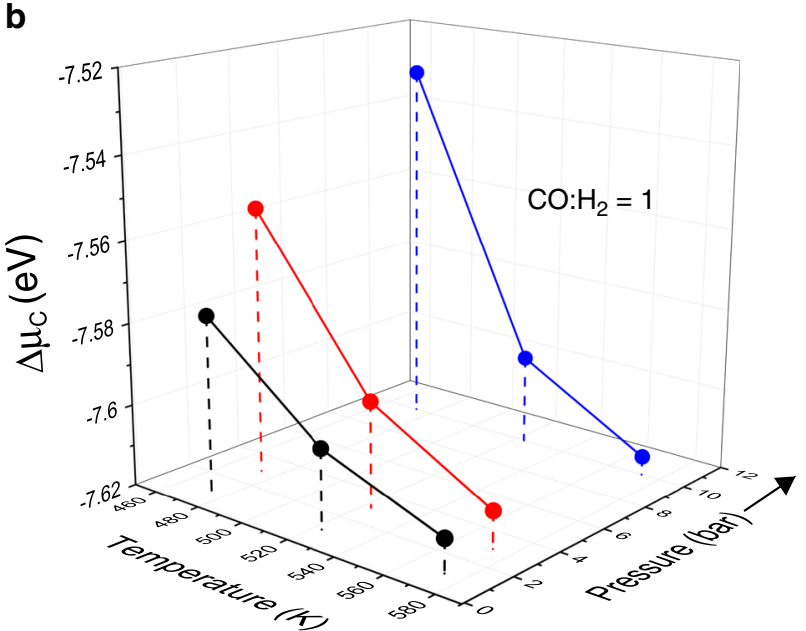

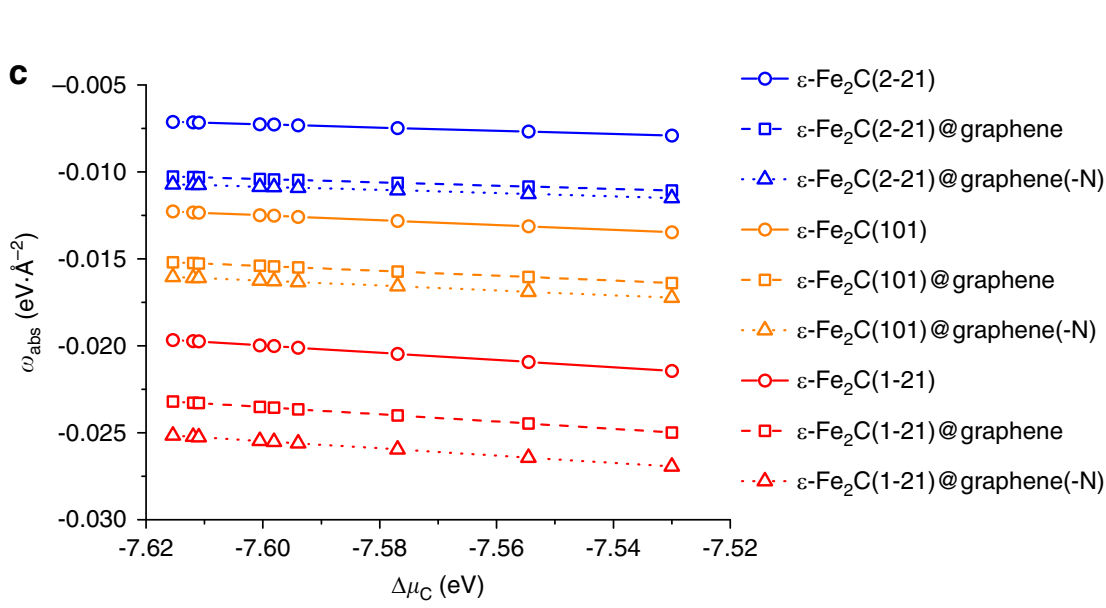

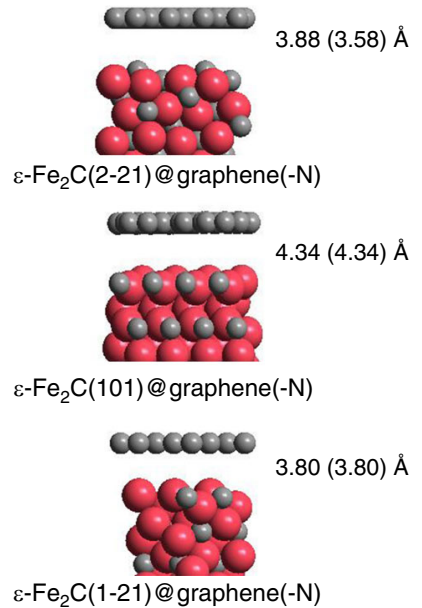

Fig. 5 DFT calculation of graphene confinement on $\mathbf{\varepsilon}-\mathbf{F e}_{\mathbf{2}} \mathbf{C}$. a Relative chemical potential of carbon $\left(\Delta \mu_{\mathrm{C}}\right)$ for carburization by $\mathrm{CO}\left(2 \mathrm{CO} \rightarrow \mathrm{C}+\mathrm{CO}{ }_{2}\right)$. b Relative chemical potential of carbon $\left(\Delta \mu_{\mathrm{C}}\right)$ for carburization by syngas $\left(4 \mathrm{CO}+4 \mathrm{H}_{2} \rightarrow 2 \mathrm{C}+\mathrm{CO}_{2}+2 \mathrm{H}_{2} \mathrm{O}+\mathrm{CH}_{4}\right)$. c Surface-normalized carbon absorption energy $\left(\omega_{\text {abs }}\right)$ of $\varepsilon-\mathrm{Fe}_{2} \mathrm{C}$ surfaces with and without graphene(-N) layers and the most stable structures labeled by the distances between $\varepsilon$-Fe ${ }_{2} \mathrm{C}$ and graphene (data in parenthesis referring to those of graphene- $\mathrm{N}$ ).

layers stabilize the metastable but very active $\varepsilon-\mathrm{Fe}_{2} \mathrm{C}$ phase. The unique confinement structure $\left(\varepsilon-\mathrm{Fe}_{2} \mathrm{C} @ g r a p h e n e\right)$ can inhibit the formation of an amorphous carbon layer that converts catalytically active $\varepsilon-\mathrm{Fe}_{2} \mathrm{C}$ phase to other less active carbide phases (e.g., $\chi-\mathrm{Fe}_{5} \mathrm{C}_{2}$ ). Our results and conclusion could help in the rational design of promising active phases in industrial catalysts for hydrogenation processes.

\section{Methods}

Preparation of $\boldsymbol{\theta}-\mathbf{F e}_{\mathbf{3}} \mathbf{C} @ g$ graphene. The iron carbide nanocomposites were synthesized by pyrolysis of a molten mixture of urea, glucose, and $\mathrm{Fe}\left(\mathrm{NO}_{3}\right)_{3} \cdot 9 \mathrm{H}_{2} \mathrm{O}$. In a typical synthesis, an amount of $\mathrm{Fe}\left(\mathrm{NO}_{3}\right)_{3} \bullet 9 \mathrm{H}_{2} \mathrm{O}$, corresponding to the final $\mathrm{Fe}$ loading of 30-60 wt\%, was mixed with $5.0 \mathrm{~g}$ urea and $3.0 \mathrm{~g}$ glucose at $393-433 \mathrm{~K}$ to form a transparent solution. The resultant molten mixture was heated at $453 \mathrm{~K}$ in an oven for $24 \mathrm{~h}$. The solid collected was subjected to a heat treatment in flowing $\mathrm{N}_{2}\left(10 \mathrm{~mL} \mathrm{~min}{ }^{-1}\right)$ at $673 \mathrm{~K}$ for $30 \mathrm{~min}$ and finally at the final temperatures $(773-1023 \mathrm{~K})$ for another $2 \mathrm{~h}$.

Preparation of $\boldsymbol{\varepsilon}-\mathbf{F e}_{\mathbf{2}} \mathbf{C} @$ graphene. The $\theta-\mathrm{Fe}_{3} \mathrm{C} @$ graphene samples obtained above were reduced in a flow of $3 \mathrm{~L} \mathrm{~g}_{\text {cat }}{ }^{-1} \mathrm{~h}^{-1}$ of $\mathrm{H}_{2}$ at $623 \mathrm{~K}$ for $3 \mathrm{~h}$ (denoted as Fe@graphene), and then the carbonization in a flow of $64 \mathrm{~L} \mathrm{~g}_{\text {cat }}{ }^{-1} \mathrm{~h}^{-1}$ of syngas $\left(\mathrm{H}_{2} / \mathrm{CO}=1\right)$ at $573 \mathrm{~K}$ for $10 \sim 400 \mathrm{~h}$ (denoted as $\varepsilon-\mathrm{Fe}_{2} \mathrm{C} @$ graphene).

Catalyst Characterization. The size and morphology of samples were determined using a FEI Tecnai G20 transmission electron microscope operated at $200 \mathrm{kV}$ and a
Hitachi SU8000 field emission scanning electron microscope at an accelerating voltage of $15 \mathrm{kV}$.

The ${ }^{57} \mathrm{Fe}$ Mössbauer measurements were performed at room temperature or 77 $\mathrm{K}$ using a conventional spectrometer (Germany, Wissel MS-500) in transmission geometry with constant acceleration mode. A $57 \mathrm{Co}(\mathrm{Rh})$ source with an activity of $25 \mathrm{mCi}$ was used. The velocity calibration was done with a room temperature $\mathrm{\alpha}-\mathrm{Fe}$ absorber. The spectra were fitted by the software Recoil using Lorentzian Multiplet Analysis. The samples were passivated in flowing $1 \% \mathrm{O}_{2} / \mathrm{N}_{2}$ for $1 \mathrm{~h}$ at room temperature prior to air exposure and being sealed in a sample holder with paraffin wax for Mössbauer spectroscopy measurements.

The CO chemisorption was performed using a Micromeritics AutoChem II 2920 unit. Before CO chemisorption, $0.1 \mathrm{~g}$ of catalyst was reduced under flowing pure hydrogen at $623 \mathrm{~K}$ for $3 \mathrm{~h}$ and then carburized in syngas $\left(\mathrm{H}_{2} / \mathrm{CO}=1\right)$ at $573 \mathrm{~K}$ for $5 \mathrm{~h}$. Subsequently, the adsorbed species were removed by flowing $\mathrm{He}$ at $823 \mathrm{~K}$ for $2 \mathrm{~h}$. The samples were cooled to $308 \mathrm{~K}$, then CO chemisorption experiment was conducted. The average CO:Fe stoichiometry was assumed 1:2. For $\theta-\mathrm{Fe}_{3} \mathrm{C} @$ graphene catalyst, reduction and carburization processes are eliminated.

For CO temperature-programmed desorption (CO-TPD), $0.1 \mathrm{~g}$ of catalyst was reduced under flowing pure hydrogen at $623 \mathrm{~K}$ for $3 \mathrm{~h}$ and then carburized in syngas $\left(\mathrm{H}_{2} / \mathrm{CO}=1\right)$ at $573 \mathrm{~K}$ for $5 \mathrm{~h}$. Subsequently, the adsorbed species were removed by flowing $\mathrm{He}$ at $573 \mathrm{~K}$ for $2 \mathrm{~h}$. The samples were cooled to $308 \mathrm{~K}$. At this temperature, the carburized sample was flushed with $\mathrm{CO}$ for $1 \mathrm{~h}$ and consequently purged with He until the baseline of CO signal leveled off. Finally, the sample was heated to $1,073 \mathrm{~K}$ at a ramp of $10 \mathrm{~K} \mathrm{~min}{ }^{-1}$. For $\theta-\mathrm{Fe}_{3} \mathrm{C} @$ graphene catalyst, reduction and carburization processes are eliminated.

$\mathrm{X}$-ray diffraction (XRD) patterns of the samples were recorded on a Bruker D8 powder diffractometer equipped with a $\mathrm{Cu}-\mathrm{Ka}$ source operated at $40 \mathrm{kV}$ and 40 $\mathrm{mA}$ and a Vantec-1 detector. 
X-ray photoelectron spectroscopy (XPS) measurements were conducted on a VG Multilab 2000 photoelectron spectrometer using $\mathrm{Al} K_{\alpha}$ radiation operated under vacuum $\left(2 \times 10^{-6} \mathrm{~Pa}\right)$ with the binding energy $(\mathrm{BE})$ calibrated using the $\mathrm{C} 1 \mathrm{~s}$ peak at $284.6 \mathrm{eV}$.

Thermogravimetric analysis (TGA) was carried out on a NETZSCH TG 209F3 TGA analyzer during temperature ramping from $303 \mathrm{~K}$ to $1,173 \mathrm{~K}$ in flowing air $\left(50 \mathrm{~mL} \mathrm{~min}{ }^{-1}\right)$ with a ramping rate of $10 \mathrm{~K} \mathrm{~min}^{-1}$.

Catalytic evaluation. Fischer-Tropsch synthesis was performed in a stainless steel fixed-bed reactor (i.d. $=12 \mathrm{~mm}$ ). Catalysts were diluted with inert $\mathrm{SiC}$ particles in a mass ratio of 1:10 prior to testing. The diluted catalysts $(5.5 \mathrm{~g})$ were pre-treated in flowing $\mathrm{H}_{2}\left(10 \mathrm{~mL} \mathrm{~min}^{-1}\right)$ at $623 \mathrm{~K}$ for $3 \mathrm{~h}$ before reactions. The pre-treated catalysts were cooled to $373 \mathrm{~K}$ in flowing $\mathrm{H}_{2}$ before the introduction of syngas $\left(\mathrm{H}_{2} /\right.$ $\mathrm{CO}=1)$. The reaction temperature was then ramped slowly to $593 \mathrm{~K}$. The permanent gases $\left(\mathrm{H}_{2}, \mathrm{CO}, \mathrm{CO}_{2}\right)$ and light alkanes $\left(\mathrm{CH}_{4}, \mathrm{C}_{2} \mathrm{H}_{6}\right.$, etc.) in the effluent of the reactor were monitored by an online Agilent Micro GC3000A gas chromatograph (GC) equipped with the molecular sieve, Plot- $\mathrm{Q}$ and $\mathrm{Al}_{2} \mathrm{O}_{3}$ capillary columns and a TCD detector. The oil and wax products were separated using a cold trap $(271 \mathrm{~K})$ and a hot trap $(423 \mathrm{~K})$, respectively, while the aqueous products were obtained by phase separation in those traps. The oil products were analyzed using an Agilent $6890 \mathrm{~N}$ GC with a FID detector and a HP-5 column; the wax products were dissolved in $\mathrm{CS}_{2}$ and analyzed using an Agilent $7890 \mathrm{~A}$ GC equipped with a FID detector and a HT5 column; the aqueous fraction was analyzed using an Agilent 4890 GC equipped with a FID detector and a HP-Innowax column. The product selectivity was calculated based on the carbon balance.

DFT calculations. Density functional theory calculations were performed using the generalized gradient approximation Perdew-Burke- Ernzerhof of (PBE) functional $^{44}$ and projector-augmented wave (PAW) method ${ }^{45}$ as implemented in the Vienna ab initio simulation package (VASP) ${ }^{46}$. A second-order Methfessel-Paxton electron smearing scheme $($ sigma $=0.2 \mathrm{eV})$ was used because of the metallic conductor properties of iron carbide. Plane-wave kinetic energy cut off of $400 \mathrm{eV}$ is sufficiently accurate for the spin polarization calculations of the electronic properties of open-shell iron carbide. Energy and force convergence criteria were $10^{-5}$ $\mathrm{eV}$ and $0.03 \mathrm{eV} \AA^{-1}$, respectively. The most abundant $\varepsilon-\mathrm{Fe}_{2} \mathrm{C}(1-21), \varepsilon-\mathrm{Fe}_{2} \mathrm{C}(101)$, and $\varepsilon-\mathrm{Fe}_{2} \mathrm{C}(2-21)$ surfaces were taken into account. A vacuum of $15 \AA$ was used for screening the interactions vertical to the surface. The most stable configurations were selected to model the confinement effects of graphene and $\mathrm{N}$-doped graphene (graphene- $\mathrm{N}$ ) on the carburization feasibility of $\varepsilon-\mathrm{Fe}_{2} \mathrm{C}$ from metallic iron and the reaction mechanism of $\mathrm{CO}$ dissociation. The computational details are deposited in Supplementary Methods.

\section{Data availability}

The data that support the plots within this paper and other findings of this study are available from the corresponding author upon request.

Received: 4 January 2020; Accepted: 6 November 2020; Published online: 04 December 2020

\section{References}

1. Khodakov, A. Y., Chu, W. \& Fongarland, P. Advances in the development of novel cobalt Fischer-Tropsch catalysts for synthesis of long-chain hydrocarbons and clean fuels. Chem. Rev. 107, 1692-1744 (2007).

2. Cheng, K. et al. Advances in catalysis for syngas conversion to hydrocarbons. Adv. Catal. 60, 125-208 (2017).

3. de Smit, E. \& Weckhuysen, B. M. The renaissance of iron-based FischerTropsch synthesis: on the multifaceted catalyst deactivation behaviour. Chem. Soc. Rev. 37, 2758-2781 (2008)

4. Lyu, S. et al. Role of active phase in Fischer-Tropsch synthesis: experimental evidence of CO activation over single-phase cobalt catalysts. ACS Catal. 8, 7787-7798 (2018).

5. Zhou, W. et al. New horizon in $\mathrm{C} 1$ chemistry: breaking the selectivity limitation in transformation of syngas and hydrogenation of $\mathrm{CO}_{2}$ into hydrocarbon chemicals and fuels. Chem. Soc. Rev. 48, 3193-3228 (2019).

6. Bao, J., Yang, G., Yoneyama, Y. \& Tsubaki, N. Significant advances in $\mathrm{C} 1$ catalysis: highly efficient catalysts and catalytic reactions. ACS Catal. $\mathbf{9}$, 3026-3053 (2019).

7. Xu, J., Yang, Y. \& Li, Y. Fischer-Tropsch synthesis process development: steps from fundamentals to industrial processes. Curr. Opin. Chem. Eng. 2, 354-363 (2013).

8. Chen, W., Fan, Z., Pan, X. \& Bao, X. Effect of confinement in carbon nanotubes on the activity of Fischer-Tropsch iron catalyst. J. Am. Chem. Soc. 130, 9414-9419 (2008)
9. Yu, G. et al. $\mathrm{Fe}_{\mathrm{x}} \mathrm{O}_{\mathrm{y}} @ \mathrm{C}$ spheres as an excellent catalyst for Fischer-Tropsch synthesis. J. Am. Chem. Soc. 132, 935-937 (2009).

10. Torres Galvis, H. M. et al. Supported iron nanoparticles as catalysts for sustainable production of lower olefins. Science 335, 835-838 (2012).

11. Schulte, H. J., Graf, B., Xia, W. \& Muhler, M. Nitrogen- and oxygenfunctionalized multiwalled carbon nanotubes used as support in ironcatalyzed, high-temperature Fischer-Tropsch Synthesis. ChemCatChem 4, 350-355 (2012).

12. Santos, V. P. et al. Metal organic framework-mediated synthesis of highly active and stable Fischer-Tropsch catalysts. Nat. Commun. 6, 6451-6458 (2015).

13. An, B., Cheng, K., Wang, C., Wang, Y. \& Lin, W. Pyrolysis of metal-organic frameworks to $\mathrm{Fe}_{3} \mathrm{O}_{4} @ \mathrm{Fe}_{5} \mathrm{C}_{2}$ core-shell nanoparticles for Fischer-Tropsch synthesis. ACS Catal. 6, 3610-3618 (2016).

14. Chen, X., Deng, D., Pan, X., Hu, Y. \& Bao, X. N-doped graphene as an electron donor of iron catalysts for CO hydrogenation to light olefins. Chem. Commun. 51, 217-220 (2015).

15. Niemantsverdriet, J. W., Van der Kraan, A. M., Van Dijk, W. L. \& Van der Baan, H. S. Behavior of metallic iron catalysts during Fischer-Tropsch synthesis studied with Mössbauer spectroscopy, X-ray diffraction, carbon content determination, and reaction kinetic measurements. J. Phys. Chem. 84, 3363-3370 (1980).

16. Niemantsverdriet, J. W. \& van der Kraan, A. M. On the time-dependent behavior of iron catalysts in Fischer-Tropsch synthesis. J. Catal. 72, 385-388 (1981).

17. Rao, K. R. P. M. et al. Mössbauer study of iron Fischer-Tropsch catalysts during activation and synthesis. Energy Fuels 10, 546-551 (1996).

18. Xu, J. \& Bartholomew, C. R. Temperature-programmed hydrogenation (TPH) and in situ Mössbauer spectroscopy studies of carbonaceous species on silicasupported iron Fischer-Tropsch catalysts. J. Phys. Chem. B 109, 2392-2403 (2005).

19. Herranz, T. et al. Genesis of iron carbides and their role in the synthesis of hydrocarbons from synthesis gas. J. Catal. 243, 199-211 (2006).

20. de Smit, E. et al. Stability and reactivity of $\varepsilon-\chi-\theta$ iron carbide catalyst phases in Fischer-Tropsch synthesis: controlling $\mu$ c. J. Am. Chem. Soc. 132, 14928-14941 (2010).

21. Puga, A. V. On the nature of active phases and sites in $\mathrm{CO}$ and $\mathrm{CO}_{2}$ hydrogenation catalysts. Catal. Sci. Technol. 8, 5681-5707 (2018).

22. Liu, X. et al. Environmental transmission electron microscopy (ETEM) studies of single iron nanoparticle carburization in synthesis gas. ACS Catal. 7, 4867-4875 (2017).

23. Lee, H. K. et al. Extremely productive iron-carbide nanoparticles on graphene flakes for CO hydrogenation reactions under harsh conditions. J. Catal. $\mathbf{3 7 8}$ 289-297 (2019).

24. Kang, S. et al. High-performance $\mathrm{Fe}_{5} \mathrm{C}_{2} @ \mathrm{CMK}-3$ nanocatalyst for selective and high-yield production of gasoline-range hydrocarbons. J. Catal. 349 66-74 (2017).

25. Yang, C., Zhao, H., Hou, Y. \& Ma, D. $\mathrm{Fe}_{5} \mathrm{C}_{2}$ nanoparticles: a facile bromideinduced synthesis and as an active phase for Fischer-Tropsch synthesis. J. Am. Chem. Soc. 134, 15814-15821 (2012).

26. Hong, $\mathrm{S}$. Y. et al. A new synthesis of carbon encapsulated $\mathrm{Fe}_{5} \mathrm{C}_{2}$ nanoparticles for high-temperature Fischer-Tropsch synthesis. Nanoscale 7, 16616-16620 (2015).

27. Cheng, J. et al. Density functional theory study of iron and cobalt carbides for Fischer-Tropsch synthesis. J. Phys. Chem. C. 114, 1085-1093 (2010). M.

28. Zhao, S. et al. Surface morphology of Hägg iron carbide $\left(\chi-\mathrm{Fe}_{5} \mathrm{C}_{2}\right)$ from ab initio atomistic thermodynamics. J. Catal. 294, 47-53 (2012).

29. Xu, K. et al. $\varepsilon$-Iron carbide as a low-temperature Fischer-Tropsch synthesis catalyst. Nat. Commun. 5, 5783-5783 (2014).

30. Wang, P. et al. Synthesis of stable and low- $\mathrm{CO}_{2}$ selective $\varepsilon$-iron carbide Fischer-Tropsch catalysts. Sci. Adv. 4, eaau2947 (2018).

31. Jin, Y. \& Datye, A. K. Phase transformations in iron Fischer-Tropsch catalysts during temperature-programmed reduction. J. Catal. 196, 8-17 (2000).

32. de Smit, E. et al. On the surface chemistry of iron oxides in reactive gas atmospheres. Angew. Chem. Int. Ed. 50, 1584-1588 (2011).

33. Duong, D. L. et al. Probing graphene grain boundaries with optical microscopy. Nature 490, 235-239 (2012).

34. Fu, Q. \& Bao, X. Surface chemistry and catalysis confined under twodimensional materials. Chem. Soc. Rev. 46, 1842-1874 (2017).

35. Huang, F. et al. Anchoring $\mathrm{Cu}_{1}$ species over nanodiamond-graphene for semihydrogenation of acetylene. Nat. Commun. 10, 1-7 (2019).

36. Ni, Z., Wang, Y., Yu, T. \& Shen, Z. Raman spectroscopy and imaging of graphene. Nano Res. 1, 273-291 (2008).

37. Sheng, Z. H. et al. Catalyst-free synthesis of nitrogen-doped graphene via thermal annealing graphite oxide with melamine and its excellent electrocatalysis. ACS Nano 5, 4350-4358 (2011).

38. Xiong, H. et al. Fischer-Tropsch synthesis: Iron catalysts supported on Ndoped carbon spheres prepared by chemical vapor deposition and hydrothermal approaches. J. Catal. 311, 80-87 (2014). 
39. Lu, J. et al. Promotion effects of nitrogen doping into carbon nanotubes on supported iron Fischer-Tropsch catalysts for lower olefins. ACS Catal. 4, 613-621 (2014).

40. Xie, J. et al. Size and promoter effects on stability of carbon-nanofibersupported iron-based Fischer-Tropsch catalysts. ACS Catal. 6, 3147-3157 (2016).

41. Torres Galvis, H. M. et al. Iron particle size effects for direct production of lower olefins from synthesis gas. J. Am. Chem. Soc. 134, 16207-16215 (2012).

42. Webster, C. E., Drago, A. R. \& Zerner, M. C. Molecular dimensions for adsorptives. J. Am. Chem. Soc. 120, 5509-5516 (1998).

43. Yu, Y. \& Gao, G. Lennard-Jones chain model for self-diffusion of n-Alkanes. Int. J. Thermophys. 21, 57-70 (2000).

44. Perdew, J. P., Burke, K. \& Ernzerhof, M. Generalized gradient approximation made simple. Phys. Rev. Lett. 77, 3865-3868 (1996).

45. Blöchl, P. E. Projector augmented-wave method. Phys. Rev. B 50, 17953-17979 (1994).

46. Kresse, G. \& Furthmüller, J. Efficient iterative schemes for ab initio totalenergy calculations using a plane-wave basis set. Phys. Rev. B 54, 11169-11186 (1996).

\section{Acknowledgements}

We acknowledge Dr. Kenneth G. Rappé (Pacific Northwest National Laboratory), Prof. Norbert Kruse (Washington State University), Prof. Zhao-Xu Chen (Nanjing University), and Prof. Jianyu Huang (Yanshan University) for helpful discussions. This work was supported by the National Natural Science Foundation of China (22072184, 21972170), the Joint Fund of National Natural Science Foundation of China (U1463210).

\section{Author contributions}

L.W. and J.L. supervised the whole project and designed the study. L.W., J.L., and Y.W. co-wrote the manuscript. S. L., S.Y., and J.C. performed most of the experiments and analyzed the experimental data. Z.L. helped to do the DFT simulations. Y.Z. performed reaction testing. All the authors discussed the results and assisted during the manuscript preparation.

\section{Competing interests}

The authors declare no competing interests.

\section{Additional information}

Supplementary information is available for this paper at https://doi.org/10.1038/s41467020-20068-5.

Correspondence and requests for materials should be addressed to L.W., J.L. or Y.W.

Peer review information Nature Communications thanks the anonymous reviewers for their contribution to the peer review of this work.

Reprints and permission information is available at http://www.nature.com/reprints

Publisher's note Springer Nature remains neutral with regard to jurisdictional claims in published maps and institutional affiliations.

(c) (i) Open Access This article is licensed under a Creative Commons Attribution 4.0 International License, which permits use, sharing, adaptation, distribution and reproduction in any medium or format, as long as you give appropriate credit to the original author(s) and the source, provide a link to the Creative Commons license, and indicate if changes were made. The images or other third party material in this article are included in the article's Creative Commons license, unless indicated otherwise in a credit line to the material. If material is not included in the article's Creative Commons license and your intended use is not permitted by statutory regulation or exceeds the permitted use, you will need to obtain permission directly from the copyright holder. To view a copy of this license, visit http://creativecommons.org/ licenses/by/4.0/.

(C) The Author(s) 2020 